\title{
MERCADO PERUANO DE LÁCTEOS
}

\author{
Rolando Piskulich ${ }^{1}$
}

El Mercado de Lácteosen el Perú

\section{La Demanda}

Para los productos lácteos nacionales se observa un crecimiento en el 2000 de $17.34 \%$ con respecto a 1999 , y un crecimiento de $39.01 \%$ en el periodo 1995-2000.

El mercado deproductoslácteosimportados muestra un decrecimiento de $26.61 \%$ en el 2000 con respecto a 1999 , y un decrecimien to del $48.72 \%$ parael periodo $1995-2000$.

El mercado total (nacional + importado) muestra un crecimiento de $10.73 \%$ para el 2000 con respecto a 1999 y un crecimiento $17.73 \%$ para el periodo $1995-2000$.

\section{Consumo Per cápita}

El consumo per cápita de leche en el Perú es de $45 \mathrm{~kg} / \mathrm{hab} / \mathrm{anno}$, nivel que resulta bajo comparado con el consumo mínimo re comendado por FAO de $120 \mathrm{~kg} / \mathrm{hab} / \mathrm{año}$. En el Cuadro 1 se puede apreciar el consumo per cápita de leche en el Perú durante los últimos diez años. Nótese que durante este periodo no havariado sustancial mente.

Consumo Per cápita de Derivados Lácteos

Los derivados lácteos en el Perú también tienen un consumo per cápita bajo. Así por ejemplo en el caso dequesos parael Perú se tiene un consumo per cápita de 0.24 kg/ hab/año, mientras que en Brasil, Argentina, Estados Unidos y Francia es de 2.67, 10.53, 12.79 y 21.4 respectivamente. Para el caso de la mantequilla se tiene que en el Perú el consumo per cápita es de 0.06 kg/hab/año, mientras que en Brasil, Argentina, Estados Uni dos y Francia dicho consumo es de 0.47, 1.28, 1.95 y 8.6, respectivamente. Para el caso del Yogurt, el consumo per cápita en el Perú es de $0.48 \mathrm{~kg} / \mathrm{hab} / \mathrm{año}$, mientras queen países europeos como Francia y Alemania esteconsumo es deaproximadamente $10 \mathrm{~kg} /$ hab/año (Fuente: Dairy World Markets and Trade, USDA, enero de 1997).

Esta real idad guarda correspondencia con el marco general de la situación al imentaria del país. Como referenciael Penú está cal ificado por la FAO, en el documento Evaluación delaSeguridadAlimentaria(FAO, enero de 1996), como un país en que $\mathrm{e}$ suministro deal imentos empeoró desde 196971, en quesesumi nistraba 2,316 Cal/hab/día a un suministro de 1,882 Cal/hab/día en los años 1990-1992. En esta clasificación seencuentraal mismo nivel de países como Haití, Angola, Bangladesh, etc. Esta realidad del Penú debe mejorarse en el futuro. Cual quier esfuerzo que contribuya a mejorar los nive les de consumo deal imentos, como el quese plantea para el caso de los lácteos, servirá para traer bi enestar a la pobl ación y mejorar la realidad del país.

\section{La Oferta}

El Perú, comparado con sus vecinos de Sudamérica, es uno de los países de más baja producción de leche cruda por habitante. En el Cuadro 2 se observa que mientras queUruguay tiene una producción de $459 \mathrm{~kg} /$ hab/año, siendo la más alta de Sudamérica, seguida por Argentina con $242 \mathrm{~kg} / \mathrm{hab} / \mathrm{añoy}$ Chilecon 154kg/hab/año; el Penú solamente tieneuna producción de 37 kg/hab/año, y Bo-

1 Ingeniero Agrónomo, MSc 
Cuadro 1. Perú: Consumo per cápita deleche 1990-1996

\begin{tabular}{|c|c|c|c|c|c|c|c|c|}
\hline \multirow[b]{2}{*}{ Año } & \multirow[b]{2}{*}{$\begin{array}{l}\text { Población } \\
\text { (miles) }\end{array}$} & \multirow[b]{2}{*}{$\begin{array}{l}\text { Total } \\
\text { leche }\end{array}$} & \multirow[b]{2}{*}{$\begin{array}{l}\text { Leche } \\
\text { fresca }\end{array}$} & \multirow[b]{2}{*}{$\begin{array}{l}\text { Sub } \\
\text { total }\end{array}$} & \multicolumn{4}{|c|}{ Lechefluida (kg) } \\
\hline & & & & & $\begin{array}{c}\text { Polvo } \\
\text { descremada } \\
\text { (LDP) }\end{array}$ & $\begin{array}{l}\text { Polvo } \\
\text { entera } \\
\text { (LEP) }\end{array}$ & $\begin{array}{l}\text { Grasa } \\
\text { anhidra }\end{array}$ & $\begin{array}{l}\text { Leche } \\
\text { evaporada }\end{array}$ \\
\hline 1990 & 21,569 & 45.3 & 22.5 & 22.8 & 4.3 & 6.1 & 1.7 & 10.7 \\
\hline 1991 & 21,966 & 43.6 & 22.4 & 21.2 & 3.7 & 5.7 & 0.7 & 11.1 \\
\hline 1992 & 22,354 & 46.5 & 21.5 & 25.0 & 3.2 & 9.4 & 1.2 & 11.2 \\
\hline 1993 & 22,740 & 49.5 & 23.0 & 26.6 & 3.7 & 11.3 & 0.8 & 10.8 \\
\hline 1994 & 23,130 & 50.1 & 23.4 & 26.7 & 3.9 & 9.6 & 1.1 & 12.1 \\
\hline 1995 & 23,531 & 56.2 & 23.6 & 32.6 & 3.5 & 14.4 & 0.7 & 13.9 \\
\hline 1996 & 23,946 & 46.1 & & & & & & \\
\hline 1997 & 24,371 & 46.1 & & & & & & \\
\hline 1998 & 24,800 & 46.7 & & & & & & \\
\hline 1999 & 25,232 & 45.7 & & & & & & \\
\hline 2000 & 25,661 & 45.8 & & & & & & \\
\hline
\end{tabular}

livia 23 kg/hab/año. Ambos paísestienen los indicadores mas bajos de producción per cápita de leche de Sudamérica.

Cómo Mejorar los Niveles de Consumo de Lácteosen el Perú

Para mejorar los indicadores de consur mo de leche en el Perú es necesario mejorar la oferta de leche en sus aspectos de volumen, cal idad y precio.

O bjetivos de la Industria Láctea Peruana

El objetivo general detodos los agentes que intervienen en el sector lácteo es abastecer a la población peruana de leche y derivados lácteos en cantidad suficiente, con productos de calidad y a precios competitivos, en el contexto de un libre mercado.

Alcanzar esteobjetivo significamejorar progresivamenteel consumo nacional per cápita de lácteos, que se encuentra apenas en un 37\% del mínimo establecido por FAO (120 kg/hab/año).

Para lograr el objetivo general es ne cesario al canzar objetivos específicos quese ajusten al marco de referencia que caracterizará en el futuro el sistema de producción delácteos, dentro del contexto dela realidad nacional y dentro de sus objetivos como nación. Estosobjetivos específicos son:

- Autoabastecer el mercado nacional en su nivel de oferta actual, mediante el incre mento dela producción nacional (Producir eindustrializar 1'175,658 de TM de leche anualmente).

- Aumentar la oferta nacional de lácteos, hasta lograr un nivel de consumo per cápita anual mínimo de 96 kg/hab/año (Producir e industrializar 2' 400,000 TM de leche anual mente).

- Revertirlasituación del Perúdeimportador delácteos, convirtiéndolo en un exportador. 
Cuadro 2. Producción per cápita de lecheen Sudamérica

\begin{tabular}{lrcc}
\hline País & $\begin{array}{c}\text { Producción de } \\
\text { leche(TM) }\end{array}$ & $\begin{array}{c}\text { Población } \\
\text { (millones) }\end{array}$ & $\begin{array}{c}\text { Producción deleche } \\
\text { (kilos/hab) }\end{array}$ \\
\hline Perú & 900,000 & 23.9 & 37.66 \\
Argentina & $8,000,000$ & 33.0 & 242.42 \\
Uruguay & $1,393,000$ & 3.0 & 459.74 \\
Brasil & $17,000.000$ & 160.0 & 106.25 \\
Chile & $2,009,000$ & 13.0 & 154.54 \\
Bolivia & 160,000 & 6.7 & 23.88 \\
Colombia & $3,230,000$ & 35.0 & 92.29 \\
Ecuador & $1,030,000$ & 10.9 & 94.40 \\
\hline
\end{tabular}

Fuente: FEPALE

Cuantificación de OBjetivos de LA I ndustria Láctea Peruana

En el Perú se oferta 1'175,658 TM deproductos lácteos en su equival enteen le che fluida, en sus diferentes formas de presentación (fresca, pasteurizada, evaporada, quesos, yogurt, etc.). Esta leche proviene de 624,518TM queofrecelaindustrianacional, 74,919TM quevienecomo productosimportados, y 477,123TM queprovienedeconsumo directo o de la industria artesanal. Nótese también que la industria nacional utiliza 408,331TM de leche fresca nacional y 218,188 TM deleche queimporta en forma de leche en polvo (Nota: $1 \mathrm{~kg}$ de leche en polvo $=8.5 \mathrm{~kg}$ de leche fluida). En este esquema el componente importado lo componen los 216,188TM queusalaindustriay las 74,419 TM que ingresan como producto importado.

Las 1,175,658 TM consumidas representan un consumo per cápita anual del orden de $45 \mathrm{~kg} / \mathrm{hab}$. En términos porcentual es se tiene, que del consumo total, el $40 \%$ es lechenacional no industrializadaformalmente (leche fresca y productos artesanales), el 53\% es leche nacional industrial izada localmente (para elaborar este 53\% se usa 35\% de leche importada) y $6 \%$ proviene de derivados lácteos importados.
Como este indicador plantea una tasa deincremento muy el evada parael actual hato lechero nacional, es necesario buscar opciones de sol ución más realistas.

Para al canzar los objetivos del sector lácteo nacional se requiere real izar una mejora del rendimiento del hato nacional existente e introducir ganado de al to rendimiento. En el Cuadro 3 se presenta una simula ción, queconsisteenmejorar el rendimiento promedio nacional de $1,451 \mathrm{~kg} / \mathrm{vaca} / \mathrm{año}$ en $\mathrm{l}$ hato de 723,000 cabezas, en un $7 \%$ anual. Se asumequela mejora de productividad selogrará reemplazando vacas de baja producción por alta producción, y también mejorando laalimentación, sani dad y reproducción. Mejorando el rendimiento del hato nacional, sepodría tener en un plazo deaproximadamente6años, lechefresca nacional para cubrir la demanda actual.

En el Cuadro 3 se presenta también el resultado deintroducir 6,000 vacas deal to $r e n-$ dimiento $(6,500 \mathrm{~kg} / \mathrm{vaca} / \mathrm{año})$ al hato nacional . Estopermitiría, si ademés selograel incremento de $7 \%$ anual del hato nacional, una producción de1,179,999 TM al cuarto año, lo quecurbrirála actual demanda deleche.

Lasopciones anteriormenteexpuestas, permiten al canzar el objetivo delograr queel Perú se autoabastezca de leche, a sus actua- 
Cuadro 3. Simulación del hato lechero requerido para alcarzar los dbjeivos planteados

\begin{tabular}{|c|c|c|c|c|c|c|c|}
\hline \multicolumn{3}{|c|}{$\begin{array}{l}\text { Incremento deProducción } \\
\text { Nacional en Basea Rendimiento } \\
\text { Hđto Adual: } 723,000 \text { vacas lecheras } \\
\text { Rend Actual: } 451 \text { kg/vaca/año } \\
\text { Incremento: } 7 \% \text { anud derendimiento }\end{array}$} & \multicolumn{5}{|c|}{$\begin{array}{l}\text { Incremento deProducción Nacional en Base } \\
\text { alncremento deHato } \\
\text { Ingreso al Hato de6,000 Vacas/Año } \\
\text { Rendimiento: 6,500 kg/vaca/año } \\
\text { Precio promedio por vaca US\$ 2,000.00 }\end{array}$} \\
\hline & $\begin{array}{l}\text { Rendi- } \\
\text { miento }\end{array}$ & $\begin{array}{l}\text { Produc. } \\
\text { deLeche } \\
\text { (A) }\end{array}$ & $\begin{array}{l}\text { Ingreso } \\
\text { al hato }\end{array}$ & $\begin{array}{c}\text { Hato } \\
\text { Resultante }\end{array}$ & $\begin{array}{l}\text { Produc. } \\
\text { deleche } \\
\text { (B) }\end{array}$ & $\begin{array}{l}\text { Valor de } \\
\text { inversión }\end{array}$ & $\begin{array}{l}\text { Produc. } \\
\text { acumil. }\end{array}$ \\
\hline Año & KgNaca/Año & $\mathrm{TM}^{*}$ & Vacas & Vacas & TM & US\$ & $(A+B)(T M)$ \\
\hline 2001 & 1,451 & & & 6,000 & 26,000 & & 911,454 \\
\hline 2002 & 1,553 & 947, & 6,000 & 11,820 & 51,000 & $12,000,000$ & 998,436 \\
\hline 2003 & 1,661 & $1,013,756$ & 6,000 & 17,474 & 74,000 & $12,000,000$ & 1,087,756 \\
\hline 2004 & 1 & $1,084,719$ & 6,000 & 24,067 & 95,000 & $12,000,000$ & $1,179,719$ \\
\hline 2005 & 2 & 1,160 & 6,000 & 29,949 & 114,000 & $12,000,000$ & $1,274,650$ \\
\hline 2006 & 2,035 & $1,241,895$ & 6,000 & 35,018 & 127,000 & $12,000,000$ & 1,368,895 \\
\hline 2007 & 2,178 & $1,328,828$ & 6,000 & 39,193 & 142,000 & $12,000,000$ & $1,470,828$ \\
\hline 2008 & 2,330 & $1,421,846$ & 6,000 & 43,512 & 157,000 & $12,000,000$ & $1,578,846$ \\
\hline 2009 & 2,493 & $1,521,375$ & 6,000 & 47,685 & 172,000 & $12,000,000$ & $1,693,375$ \\
\hline 2010 & 2,668 & 1,๔27,871 & 6,000 & 51,480 & 200,000 & $12,000,000$ & $1,827,871$ \\
\hline
\end{tabular}

* Se considera el $80 \%$ de la producción, el restante 20 \% es para alimentación de terneraje y mermas

lesniveles deconsumo, en un plazo deseiso cuatro años, dependiendo dela opción quese escoja.

Nótese que si se escoge la opción de introducir nuevos vientres dealta producción habría espacio para24,000 vacas en los próximos cuatro años, que sería para cubrir una demanda que ya existe actualmente. Esta metaresultadifícil deal canzar por el costoy las implicancias técnicas que conlleva. Por ello deben plantearse objetivos más modestos, que permitan ir avanzando progresivamenteenel logro del gran objetivo del sector.

Si consideramos un costo unitario por vaca de US $\$ 2,000$ (sin IGV ni arance), lograr el segundo objetivo planteado en este documento tendría un costo de 12 millones de dólares anuales, y un costo total de 120 millones de dólares en los diez años (este gasto no contempla gastos operativos ni de al imentación). A esta cifraes necesario agre garleel costo del programa para incrementar el rendimiento promedio por vaca del hato nacional.

\section{Conclusiones}

- El mercado delácteos en el Perú está en expansión.

- El Perú no seautoabastece delechey su consumo per cápita es muy bajo, lo que define un mercado potencial de aproximadamente 350 mil TM anuales para sustituir importaciones y 2,000,000 TM para incrementar $\mathrm{e}$ actual consumo per cápita a 120 kg/hab/año. 